INDO GLOBAL JOURNAL OF

PHARMACEUTICAL SCIENCES

ISSN 2249- 1023

\title{
Exploring Arabidopsis - Magnaporthe oryzae Pathosystem to Unravel Nonhost Resistance Factors Against Rice Blast
}

\author{
Eram Sultan, Kalpana Dalei, Daraksha Parween, Binod Bihari Sahu * \\ Department of Life Science, National Institute of Technology Rourkela, Odisha 769008, India
}

Address for Correspondance: Binod Bihari Sahu, binodbiharisahu@gmail.com

Keywords Rice

Blast; Arabidopsis;

Magnaporthe

oryzae; Nonhost

Resistance;

Penetration.

\begin{abstract}
Plants are under constant biotic stress by a myriad of pathogens of which rice blast, caused by Magnaporthe oryzae, is the most devastating, culminating in severe crop loss around the globe. Rice is a major food crop cultivated across the world and the rising per capita consumption in accordance with the growing population pursue serious attention towards disease-free sustainable cultivation. Plant-pathogen interaction may be compatible if the pathogen is able to breach the inducible defense responses of the host. However, in a nonhost, there exists a critical molecular interplay that mount effective resistance responses. This suggests that nonhost resistance is governed by the presence of genetic elements that diverged during evolution and can be utilized biotechnologically to engineer crops for resistance against pathogens. Arabidopsis thaliana, an established nonhost against M. oryzae involve several genes including PEN2, PMR5, MLO2 and AGB1 to evoke defense responses in an unclear fashion. The present work demonstrates compromised penetration resistance against $M$. oryzae in pen2-3 mutants suggesting its role in pre-invasion resistance. Also, the timing for the onset of defense response was studied in terms of oxidative burst visualization by $3,3^{\prime}$-diaminobenzidine and nitro blue tetrazolium staining. Further, enzyme activities of catalase, superoxide dismutase and peroxidase were also determined spectrophotometrically. These experiments suggested that ROS generation was maximum during the early hours of infection $(>=24 \mathrm{~h})$ in the wild type Arabidopsis (Col-0). Further, screening of other Arabidopsis mutants will contribute to decipher post-penetration genes and clarify the nonhost resistance mechanism elicited by Arabidopsis against M. oryzae. (C) 2016 iGlobal Research and Publishing Foundation. All rights reserved.
\end{abstract}

Conference Proceedings: International Conference on Advances in Plant and Microbial Biotechnology (PMB2017); JIIT, Noida: February 02-04, 2017

Indo Global Journal of Pharmaceutical Sciences( ISSN 22491023 ; CODEN- IGJPAI; NLM ID: 101610675) indexed and abstracted in EMBASE(Elsevier), SCIRUS(Elsevier),CABI, CAB Abstracts, Chemical Abstract Services(CAS), American Chemical Society(ACS), Index Copernicus, EBSCO, DOAJ, Google Scholar and many more. For further details, visit http://iglobaljournal.com 